\title{
Primary Bronchial Bud
}

National Cancer Institute

\section{Source}

National Cancer Institute. Primary Bronchial Bud. NCI Thesaurus. Code C34260.

A left and right outpouching at the caudal end of the laryng otracheal diverticulum in the early embryo that subsequently differentiates into the bronchi and their branches in the mature lungs. 